\title{
ACCUMULATED PENSION COLLARS: A MARKET APPROACH TO REDUCING THE RISK OF INVESTMENT-BASED SOCIAL SECURITY REFORM
}

\author{
Martin Feldstein \\ Elena Ranguelova \\ Working Paper 7861 \\ http://www.nber.org/papers/w7861 \\ NATIONAL BUREAU OF ECONOMIC RESEARCH \\ 1050 Massachusetts Avenue \\ Cambridge, MA 02138 \\ August 2000
}

We are grateful to John Campbell, Zvi Bodie, George Chacko, Robert Merton and Kent Smetters for helpful discussions, to Andrew Samwick for useful comments as well as for his continued participation in providing the basic nonstochastic simulations and to Fred Edenius for help with programming. The views expressed herein are those of the authors and not necessarily those of the National Bureau of Economic Research.

(C) 2000 by Martin Feldstein and Elena Ranguelova. All rights reserved. Short sections of text, not to exceed two paragraphs, may be quoted without explicit permission provided that full credit, including $(C$ notice, is given to the source. 
Accumulated Pension Collars: A Market Approach to Reducing

the Risk of Investment-Based Social Security Reform

Martin Feldstein and Elena Ranguelova

NBER Working Paper No. 7861

August 2000

JEL No. H55, I3

\begin{abstract}
This paper shows how a new type of derivative product that could be provided by private financial markets could in principle be used to guarantee that an investment-based Social Security reform provides at least the level of real retirement income that is projected in current Social Security rules. In effect, future retirees could purchase a "put option" that guarantees that the future retirement benefit will not fall below the level projected in current Social Security law or some other chosen level. To pay for this guarantee, they would agree to give up the part of the annuity payments which exceeds a given level, effectively selling a call option on the stream of payments.

This market-based approach could be completely voluntary, leaving each individual to decide what level of guarantee he wants. The higher the minimum guarantee that the individual chooses, the more of the potentially higher returns he must give up. The financial market can thus tailor each individual's product to his own risk preferences. Alternatively, the government might require that any product that is sold as part of the investment-based Social Security reform must include at least some such market-based guarantee.

Our analysis calculates some of the tradeoffs that could be provided in today's financial markets. We show that it is feasible to protect future benefits equal to those projected in current law with a combination of the current payroll tax rate and Personal Retirement Account savings equal to 2.5 percent of covered earnings. Raising the savings rate to 3.0 percent increases substantially the amount of the return that the individual can keep, raising it to 145 percent of the currently projected level of benefits. Reducing the guarantee level to 90 percent of the projected future benefits would increase this upside potential to 150 percent of the currently projected level of benefits with a 2.5 percent saving rate and 195 percent of the currently projected benefits with a 3.0 percent saving rate.
\end{abstract}

Martin Feldstein

National Bureau of Economic Research 1050 Massachusetts Avenue

Cambridge, MA 02138

and Harvard University

msfeldst@nber.org
Elena Ranguelova

Harvard University

Contact at: NBER

1050 Massachusetts Avenue

Cambridge, MA 02138

elena@nber.org 
Accumulated Pension Collars: A Market Approach to

Reducing the Risk of Investment-Based Social Security Reform

This paper shows how a new type of derivative product that could be provided by private financial markets could in principle be used to guarantee that an investment-based Social Security reform provides at least the level of real retirement income that is projected in current Social Security rules. In effect, future retirees could purchase a "put option" that guarantees that the future retirement benefit will not fall below the level projected in current Social Security law or some other chosen level. To pay for this guarantee, they would agree to give up the part of the annuity payments which exceeds a given level, effectively selling a call option on the stream of payments.

This market-based approach could be completely voluntary, leaving each individual to decide what level of guarantee he wants. The higher the minimum guarantee that the individual chooses, the more of the potentially higher returns he must give up. The financial market can thus tailor each individual's product to his own risk preferences. Alternatively, the government might require that any product that is sold as part of the investment-based Social Security reform must include at least some such market-based guarantee.

Our analysis calculates some of the tradeoffs that could be provided in today's financial markets. We show that it is feasible to protect future benefits equal to those projected in current law with a combination of the current payroll tax rate and Personal Retirement Account savings equal to 2.5 percent of covered earnings. Raising the savings rate to 3.0 percent increases substantially the amount of the return that the individual can keep, raising it to 145 percent of the currently projected level of benefits. Reducing the guarantee level to 90 percent of the projected future benefits would increase this upside potential to 150 percent of the currently projected level of benefits with a 2.5 percent saving rate and 195 percent of the currently projected benefits with a 3.0 percent saving rate.

The present analysis thus extends several earlier studies that showed how adding investment-based Personal Retirement Accounts to traditional pay-as-you-go Social Security 
could in principle maintain the future benefits projected in current law without the sharp rise in tax rates that would otherwise be necessary if the current pay-as-you-go system remains unchanged (Feldstein and Samwick, 1997, 1998a, 1998b). Those studies assumed that the funds in the Personal Retirement Accounts earned a real rate of return of 5.5 percent, net of administrative costs. Although 5.5 percent is a relatively conservative assumption in comparison to the returns earned historically on a balanced portfolio of stocks and bonds, these earlier studies did not deal directly with the fact that future stock and bond returns are uncertain.

The issue of uncertainty in Personal Retirement Account returns was considered explicitly in Feldstein and Ranguelova (1998) and Feldstein, Ranguelova and Samwick (1999). Those papers used the historic volatility of stock and bond returns to characterize the uncertainty of future returns but did not explore the possibility of a market-based method of reducing the risk to future retirees. More specifically, during the 50 years from 1945 to 1995 a portfolio consisting of 60 percent stock (measured by the S\&P500) and 40 percent corporate bonds had a real mean logarithmic return of 5.9 percent and a standard deviation of 12.5 percent. We subtracted 40 basis points for administrative costs and used the remaining return to generate Personal Retirement Account assets and annuities for an individual who deposits a constant percent of his payroll earnings in his account each year from age 21 until retirement at age 67.

Our procedure recognized that the future mean return is itself uncertain and that, given an estimated mean return, there is annual variation in the actual returns. We therefore began our simulation by drawing a potential future mean return from a distribution with a mean of 5.5 percent and a standard deviation of 0.0175 (i.e., the 50 year sample standard deviation divided by the square root of that sample size). We then randomly generated 80 annual rates of return (for ages 21 to 100) from a distribution with this mean and a standard deviation of 12.5 percent. We used these estimated returns to simulate the accumulation of the Personal Retirement Account assets and the subsequent annual payments of a variable life annuity. We repeated this process 10,000 times and tabulated the resulting distributions of annual retirement annuities.

On the basis of these tabulated probability distributions of the annual annuities, we concluded that the risk to potential retirees would be relatively small. For example, in a mixed system in which (1) the pay-as-you-go tax pays two-thirds of the benefits projected in current 
law $^{1}$ and (2) individuals save two percent of their covered earnings in a Personal Retirement Account that is invested in the standard 60:40 stock-bond mix, a 67-year-old retiree would have an 83 percent chance of receiving at least the "benchmark" level of benefits projected in current law (from the combination of traditional Social Security and the PRA annuities) and a 93 percent chance of getting at least 90 percent of the benchmark level. ${ }^{2}$

Our analysis also examined the possibility of providing a government guarantee that the combination of the traditional pay-as-you-go benefits and the Personal Retirement Account annuities would not be less than the benchmark level of benefits. We showed that future taxpayers would assume relatively little risk if they provided such a complete guarantee to concurrent retirees. ${ }^{3}$

The current paper presents an alternative approach to dealing with the risk inherent in Personal Retirement Account annuities. This approach can completely eliminate the risk to future retirees and future taxpayers or it can be used to modify that risk. The key to this risk mitigation strategy is the use of a new kind of financial derivative specifically designed to deal with this type of annuity risk. As we noted above, future retirees purchase guarantees that their combined benefits will not be less than the benchmark level (i.e., the benefit level projected in current Social Security law) or some other level that they prefer and pay for these guarantees by giving up some part of the return above a certain higher level. If there is no return above this higher

${ }^{1}$ The current 12.4 percent payroll tax rate would be capable of paying two-thirds of the future benefits projected in current law.

${ }^{2}$ These percentages can be derived from the distribution shown in Table 1 of Feldstein and Ranguelova (1999) by noting that the variable annuity amounts corresponding to a saving rate of two percent are half of the amounts shown in the table for the four percent saving rate and by adding these PRA annuities to the traditional tax financed annuity equal to two-thirds of the future "benchmark" benefit (i.e., the benefit projected in current law.)

${ }^{3}$ More specifically, we showed that taxpayers would have only about a 50 percent chance of having to provide any guarantee payments and that even in the worst one percent of cases the guarantee payments plus the PRA savings payments and the 12.4 percent payroll tax would be less than the approximately 19 percent payroll tax that would be needed with the unreformed pay-as-you-go system to provide the same level of benefits. This way of describing the risk may understate its magnitude because of the possibility of very large low-probability losses; see Smetters (1999a) for a strong assertion of that view. 
level, the retiree pays nothing.

In the language of financial derivatives, the future retiree buys a "put option" and finances it by selling a "call option". Such a combination is referred to as a "collar." Collars are a common type of transaction in many asset markets. Some life insurance companies sell "annuity collars" in which individuals purchase a variable annuity (i.e., an annuity whose payoff depends on the level of an index of stock prices or of stock and bond prices) that contains a guaranteed minimum payment which is financed by foregoing some portion of the return above that level or some higher level. $^{4}$

Such annuity collars are however much narrower in scope than the collars required in an investment-based Social Security program. They assume a single cash premium to purchase the annuity and a payout during a fixed period of years. The guaranteed payout is a nominal amount of dollars, rather than a real amount. In contrast, the put associated with a Personal Retirement Account must guarantee a real benefit from age 67 until the individual dies. A useful collar for a Personal Retirement Account must also recognize that the retirement annuity is "purchased" by deposits to saving accounts over an entire working life. The prices at which the stocks and bonds can be purchased during these years is unknown when the Personal Retirement Account accumulation begins. This uncertain stream of purchase prices has to be taken into account in valuing the cost of the put and the value of the associated call. To distinguish this derivative pricing problem from the problem of pricing a traditional single premium collar, we refer to this as an accumulated pension collar.

Section 1 of this paper discusses the theory of evaluating such an accumulated pension collar, i.e., of calculating the amount of potential gain that must be given up in order to finance the put option, and presents results for one basic case. In this basic case, the retiree is guaranteed 100 percent of the benchmark retirement income (i.e., the amount of Social Security benefits

${ }^{4}$ See Bodie (1999) for a brief description of some of the existing annuity collars and for a more general discussion of the possible application of collars to Social Security. Although Bodie develops this theme, he does not present any estimates of the type of collars that would be appropriate for individuals who are accumulating Personal Retirement Accounts. Smetters (1999b) discusses the use of options to evaluate a Social Security trust fund invested in equities but does not deal with individual accounts. 
projected in current law) and gives up 100 percent of the PRA annuity above some critical value. We find the single critical value for all years that is consistent with the market price of risk inherent in Black-Scholes calculations. Section 2 then presents a variety of different collar combinations corresponding to different guarantee levels, saving rates, and assumptions about the risk-free rate of return. It also considers a different type of collar in which the individual keeps 100 percent of the annuity payment above a "guarantee level" (expressed as a multiple of the benchmark benefit level) up to some critical value and then keeps 50 percent above that level. Section 3 discusses some of the directions for future work that could extend this paper.

\section{Evaluating Accumulated Pension Collars}

Before presenting the general framework needed for calculating the pension collar for a Personal Retirement Account plan, it is useful to begin with a much simpler case of an individual who makes a single investment in a portfolio of stocks and bonds and will later receive a single payment. To be specific, consider someone age 45 who deposits $\$ 1,000$ in an account that is invested in a portfolio consisting of 60 percent stocks (the S\&P 500) and 40 percent corporate bonds. The historic mean real logarithmic return on such a portfolio, net of an assumed 0.4 percent annual management charge, is 5.5 percent and the standard deviation is 12.5 percent. The account will pay out its value to him in a single payment at age 65 , i.e., after 20 years. The expected value of the payout is $\$ 3,510^{5}$ in constant dollars at the initial price level (i.e., in the prices of the year when the individual was 45 years old.)

There is however substantial uncertainty about the value to which the account will grow during the 20 years. Although the mean level return is 6.27 percent $^{6}$, the actual return can be significantly below or above this level. If the individual wants to avoid the uncertainty completely, he can instead invest the initial $\$ 1,000$ in a twenty year Treasury inflation protected

${ }^{5}$ The combination of the mean logarithmic rate of return and the standard deviation imply that the expected annual rate of return is $\exp \left[0.055+0.5(0.125)^{2}\right]-1=0.0648$.

${ }^{6}$ See footnote 5 . 
bond that has a real yield of 4.0 percent. $^{7}$ This would provide a real payment at age 65 of $\$ 2,191$. There would be no risk of something less and no chance of getting something higher. By purchasing a collar, the individual can give up some of the sure return (accepting a guarantee level that is below the $\$ 2,191$ ) but in exchange has some chance of getting a higher return.

More specifically, the individual can invest in the stock-bond portfolio but then buy a put option with a strike price of $\$ 2,000$ that guarantees that his payout will be at least $\$ 2,000$. Such an option would pay him nothing if the stock-bond investment pays $\$ 2,000$ or more but would pay him the difference between $\$ 2,000$ and the actual payout of the investment if that turns out to be less than $\$ 2,000$. The cost of that put option, which can be calculated using the Black-Scholes option pricing model, depends only on the initial investment (the $\$ 1,000$ ), the volatility of the return (the standard deviation of 12.5 percent), the length of time from the investment to the payout (20 years), and the risk free rate of return. We take this risk free rate of return to be the four percent return on the Treasury Inflation Protected Security. Taken together, these parameters imply that the cost of the put option, paid in the initial year, would be $\$ 162$.

One way to pay for such a put is to sell a call option on the investment return. A call option with strike price $\mathrm{Z}$ would require the individual to pay to the buyer of the call the difference between the payout of the investment and $\mathrm{Z}$ dollars. The higher the strike price, the less the call is worth. We can again use the Black-Scholes option pricing model to find the value of $\mathrm{Z}$ that makes the price of the call option equal to the $\$ 162$ value of the put option with a $\$ 2,000$ strike price.

The collar is thus defined by the two strike prices: the strike price of the put that the individual selects to protect his minimum payout ( $\$ 2,000$ in this example) and the strike price of the call $(Z=\$ 2,611)$ that the individual must sell to pay for this put.

The problem of guaranteeing a minimum retirement income in a system that mixes a PRA

${ }^{7}$ With these Treasury Inflation Protected Securities (TIPS), the principle and the interest payments are adjusted for changes in the consumer price index. There is the reinvestment risk that the interest payments might not be reinvestable along the way at a 4 percent real return. But since the yield curve for TIPS is quite flat, such a real "stripped" bond could be created that provided a pure cumulative real return of about four percent. 
annuity and the traditional Social Security benefits is a generalization of this simple singlepremium and single-payout collar. Any PRA system would phase in gradually, with individuals who retire after the first 10 years having relatively small PRA annuities and a relatively greater dependence on the traditional pay-as-you-go Social Security benefits. We focus in this paper on the long-run situation when the tax financed benefits pay two-thirds of the benefits projected in current law, i.e., two-thirds of what we will refer to as the "benchmark" benefits. ${ }^{8}$ We take this two-thirds as available without risk (even though there is always a political risk associated with pay-as-you-go benefits ${ }^{9}$ ). We begin by investigating the use of a collar to guarantee that the combination of the PRA annuity and the traditional benefits is at least equal to the benchmark benefit ${ }^{10}$ specified for each future year by the Social Security actuaries for an individual with mean covered earnings in each year. Equivalently, we investigate the use of a collar to guarantee that the PRA annuity is at least equal to one-third of the benchmark benefit in each retirement year.

Our analysis is based on the demographic and economic projections of the Social Security actuaries. Although the unit of analysis in our calculations is the individual worker and retiree, our calculations are scaled to take into account benefits for spouses, dependents and surviving beneficiaries. The calculations also implicitly provide funds for the disability insurance program. For more details on this, see Feldstein and Samwick (1998a, 1998b).

We assume that individuals pay 2.5 percent of their covered earnings into a personal retirement account that is invested in the mix of stocks and bonds described above. When the

${ }^{8}$ This two-thirds reflects the fact that the Social Security actuaries predict that the cost of paying the projected benefits will eventually be equivalent to a payroll tax rate of 19 percent. The available 12.4 percent payroll tax revenue is two-thirds of this projected cost. Feldstein and Samwick (2000) show how the pay-as-you-go system plus the incremental tax revenue that results from the PRA accounts can finance benefits equal to those projected in current law with the pay-as-you-go tax unchanged at 12.4 percent even if 2.0 percentage points of this tax is used to finance PRA deposits.

${ }^{9}$ See McHale (1999) for a discussion of benefit reductions in key OECD countries as well as in the United States.

${ }^{10}$ Our analysis does not deal with the issue of bequests. See Feldstein and Ranguelova (1999) and Brown (1999) for discussions of pre-retirement and post-retirement bequests. 
individual reaches age 67 , the accumulated sum is converted into a variable annuity that is invested in the same assets. We use a 2.5 percent saving rate instead of the 2.0 percent that was the principle assumption in previous studies because the resulting benefits must now be used to purchase risk protection. In the previous studies, either there was no risk protection or the future taxpayers had to provide transfers when benefits fell below the benchmark level. The cost of such intergenerational transfers is avoided in the current analysis by relying on voluntary market transactions. ${ }^{11}$

Consider the problem of guaranteeing that the combined benefit from the traditional Social Security program plus the PRA annuities is at least as large as the benchmark benefit in each year of retirement. Since two-thirds of the benchmark benefits are provided by the pay-asyou-go system, this is equivalent to buying a put option for each year's PRA annuity with a strike price equal to one-third of the benchmark benefit level. We can then calculate the common strike price for a call option for the same PRA annuity payments that has the same market value as the combined put option.

A closed form solution does not exist for the value of such a pension collar based on multiyear investments during an individual's working life. Bodie's (1999) discussion about applying financial engineering to Social Security applied the traditional Black-Scholes pricing method to a much simpler version of our problem. He studied the collar defined only over the decumulation phase of the retirement program (and with the assumption of a known life expectancy.) Over that phase, the collar can be decomposed to a linear combination of put and call options which in turn can be valued directly with the Black-Scholes formula. In our "accumulated pension" collar, individuals purchase the derivative contract at age 21 when they make their first contribution to an account. ${ }^{12}$ At that time we know how many dollars they will be putting into the account in each year in the future, but we do not know how many "units" of the

\footnotetext{
${ }^{11}$ We analyze the implications of two percent and three percent saving rates in section 2 below.

${ }^{12}$ This is a plausible description of behavior only if some form of collar is mandated by law, requiring the seller of PRA investments to provide such a guarantee. We return in section 3 to the possibility that in a completely voluntary system the individual starts later or changes the nature of his guarantee level over time.
} 
stock-bond portfolio these dollars would buy for them each year. ${ }^{13}$ The pension collar as of age 21 therefore cannot be decomposed into a linear combination of puts and calls and therefore cannot be valued by the Black-Scholes formula. We need to use a numerical implementation of an alternative options pricing technique known as risk neutral valuation. This technique which we describe in the following paragraph, provides the same option value as the Black-Scholes model in the cases when both can be applied. The theoretical justification for it was first developed by Cox and Ross (1976).

A fundamental property of option prices is that they are independent of the expected return on the underlying security. The derivation of the option pricing formula relies on a single "no arbitrage" condition and makes no assumptions about individual preferences. (Black and Scholes, 1973) Because of the preference-free property, the same price of an option is valid with any kind of preferences, including risk neutral ones. This simplifies the valuation problem enormously because we can shift our calculation to a risk-neutral world and find the value of the option as a present value of its future payoffs discounted at the riskless rate. In order to do that, we must modify the average return on all risky assets to be equal to the riskless rate ${ }^{14}$ and then discount payoffs at the same risk-free rate. ${ }^{15}$ Stated somewhat differently, to calculate option values we maintain the true variability of the payoffs (the same variance of the returns per unit time) but shift the mean return to the risk-free rate of return. We further reduce the return by 40 basis points to account for administrative costs.

In our particular case, the price of a put option at age 21 on the annuity payment due at age 67 would be

${ }^{13}$ Our analysis assumes that the future path of each individual's earnings is known and that the only uncertainty is about the portfolio returns. We return to the issue of uncertain future labor income in section 3.

${ }^{14}$ The intuition here is that when we make calculations for a risk-neutral world we must assume that preferences reflect risk-neutral probabilities. In such a world, all assets, no matter how volatile, have expected returns equal to the risk-free rate of return.

${ }^{15}$ The risk neutral valuation approach of option pricing was first developed by Cox and Ross (1976). For further discussions, see Ingersoll (1987) and Merton (1990). 
where $\pi_{67}$ is the proportion of 21 year olds who will reach age $67,{ }^{16} \mathrm{E}^{*}$ signifies that the expectation is taken over the risk-neutralized distribution of asset returns, ${ }^{17} \mathrm{~B}$ is the benchmark level of benefits to be protected by the put, $a(t)$ is the annuity payment (including the riskless portion equal to two-thirds of B that is provided by the tax-financed pay-as-you-go system) and $r$ is the risk-free interest rate. The cost to the individual of all his put options would then be the actuarial sum:

$$
\left.\mathrm{P}=\sum_{\mathrm{t}=67.100} \pi_{\mathrm{t}} \mathrm{e}^{-\mathrm{r}(\mathrm{t}-21)} \mathrm{E}^{*}[\max \{\mathrm{B}-\mathrm{a}(\mathrm{t}), 0)\}\right]
$$

where $\pi_{\mathrm{t}}$ is the proportion of the initial 21 year olds who will survive to age t. ${ }^{18}$

To evaluate 1.1 and 1.2, we sample 10,000 times from the distribution of asset returns. In order to improve the efficiency of the simulated estimators in this process, we generate the initial 10,000 standard normals by generating 5,000 and combining them with their mirror image.

Given the value of the series of put options in equation 1.2, we search for the call strike price (CAP) which implies the same total value for the series of calls. For the distribution of

${ }^{16} \mathrm{We}$ assume that the future mortality rates are known and introduce no additional risk to sellers of put options and buyers of call options. Although there is in fact some uncertainty about these mortality rates, it is small relative to the market risk and could be insured separately from the investment risk at very low cost.

${ }^{17}$ Risk-neutralized in this context means that the distribution of the annuity payments is generated as we did before but with the mean return reduced to the real return on the risk free assets, $r=0.04$. In practice, taking the administrative cost into account, this means a rate of 0.036 , corresponding to the risk free rate of 0.04 . This is equivalent to using a 4 percent rate while assuming an administrative charge equal to 0.40 percent of assets. In an earlier version of this paper, presented at the August 2000 NBER Summer Institute, we used the 4 percent risk free rate without adjustment for administrative cost.

${ }^{18}$ The benefits projected for each individual in Social Security law remain constant in real value throughout the retirees life. It is not necessary therefore to distinguish different B values by age. 
payoffs a(67) at age 67 , the value at age 21 of the call option with strike price CAP (i.e., the market value of the call option that pays the buyer of the call everything in excess of the level (AP) is

$$
\mathrm{C}_{67}=\pi_{67} \mathrm{e}^{-\mathrm{r}(67-21)} \mathrm{E}^{*}[\max \{\mathrm{a}(67)-\mathrm{CAP}, 0\}]
$$

where $\mathrm{E}^{*}$ again indicates that the expectation is taken over the risk-neutralized distribution of asset returns.

The market value at age 21 of a call option with a common strike price (CAP) for all ages is therefore:

$$
\mathrm{C}=\Sigma_{\mathrm{t}=67.100} \pi_{\mathrm{t}} \mathrm{e}^{-\mathrm{r}(\mathrm{t}-21)} \mathrm{E}^{*}[\max \{\mathrm{a}(\mathrm{t})-\mathrm{CAP}, 0\}]
$$

By equating the values of the put option of equation 1.2 and the call option of equation 1.4 we can solve for the strike price CAP that is necessary to finance the desired put option with strike price $B$.

$$
\sum_{\mathrm{t}=67.100} \pi_{\mathrm{t}} \mathrm{e}^{-\mathrm{r}(\mathrm{t}-21)} \mathrm{E}^{*}[\max \{\mathrm{B}-\mathrm{a}(\mathrm{t}), 0\}]=\Sigma_{\mathrm{t}=67 . .100} \pi_{\mathrm{t}} \mathrm{e}^{-\mathrm{r}(\mathrm{t}-21)} \mathrm{E}^{*}[\max \{\mathrm{a}(\mathrm{t})-\mathrm{CAP}, 0\}]
$$

When we implement this numerically, following Campbell, Lo and MacKinley (1997), we find that the common strike price on the call option corresponding to the 2.5 percent saving rate is 116 percent of the benchmark benefit: $\mathrm{CAP}=1.16 \mathrm{~B}$.

These calculations imply that an individual with average earnings who deposits 2.5 percent of those earnings in a Personal Retirement Account invested in a 60:40 stock-bond portfolio can use that account to acquire a collar at no additional cost that guarantees that the combined benefit (from the PRA annuity and the traditional Social Security payments) will be at least 100 percent of the benchmark benefit specified in current law and can go up to 116 percent of that benchmark. More succinctly, the mixed system with a 12.4 percent tax and a 2.5 percent PRA saving rate can guarantee the benefits projected in current law and allow the individual to 
receive up to 116 percent of those benefits.

Figure 1 shows the way that this collar would work. The curved line, in the upper panel of figure 1, shows the cumulative distribution of the PRA payment at age 67. Of the 10,000 simulations, there are approximately 5200 in which the PRA payment at age 67 would be less than the benchmark level of benefits (denoted by the solid line at 1). The put would raise these payouts to the benchmark level. There are then approximately 2,600 simulations out of the 10,000 for which the payout is above the benchmark but below the cap at 1.16 times the benchmark (shown by the higher line). In these cases, the individual would receive the actual payout, an amount greater than the benchmark. In about 2,200 cases the payout would exceed 1.16 times the benchmark, shown by the curve above the higher line. In these cases, the individual would receive 1.16 times the benchmark and the seller of the collar would receive the excess. The net effect of this is shown in the lower panel of Figure 1 which presents the amount received by the individual at age 67 as a multiple of the benchmark: an amount equal to the benchmark with probability 0.52 and an amount greater than the benchmark with probability 0.48. The probability that the put raises the amount that the individual receives is 0.52 and the probability that the cap limits the amount that the individual receives is only about 0.22 .

There are of course other possible tradeoffs that the individual might prefer. In particular, the individual can choose to have higher possible benefits by accepting a lower guarantee level, saving at a higher rate, or foregoing a share of all PRA payouts in excess of the amount needed to achieve the benchmark level. We now explore some of these possibilities.

2. Effects of the Saving Rate and Guarantee Level on the Call Option Strike Price A higher PRA saving rate reduces the risk that the PRA benefits will fall below the benchmark level. As a result, the higher PRA saving rate can substantially increase the maximum amount of the annuity income that the individual can keep, i.e., the call option strike price. The higher saving rate also raises the mean level of PRA benefits that the individual keeps for any given call option strike price.

An alternative way that an individual can retain more of the retirement income (i.e., receive a higher call option strike price) is to accept a lower put option strike price (i.e., a lower guarantee level.)

Table 1 shows the call option strike prices corresponding to three different saving rates 
(2.0, 2.5 and 3.0 percent of covered earnings) and four levels of guarantees $(90,95,100$ and 105 percent of the benchmark.)

Reducing slightly the level of the guarantee substantially increases the maximum amount that the individual retiree can keep, i.e., level of the cap. Thus with a 2.5 percent saving rate, the cap rises from 116 percent of the benchmark with a 100 percent guarantee floor to 150 percent with a 90 percent floor. Raising the guarantee level to 106 percent of the benchmark requires a call option with the same 106 percent strike price; stated differently, investing in a 4 percent risk free government bond yields 106 percent of the benchmark.

Raising the saving rate also has a substantial effect on the maximum amount that the retirees can keep. With a 100 percent floor, the cap rises from 116 precent of the benchmark with a 2.5 percent saving rate to 145 percent with a three percent saving rate. A 2 percent saving rate is not enough to provide a guaranteed annuity that makes the combined benefit equal to the benchmark. To achieve that benchmark guarantee requires a saving rate of 2.16 percent or more.

There are of course a variety of other ways in which guarantees and caps can be combined. One such variation that allows greater upside gain is to share all of the gain above some threshold level. For example, the individual could obtain a put option that guarantees that the benefit is at least equal to the benchmark and in exchange give a call option that gives the holder of the call 50 percent of the annuity payment in excess of some threshold level. With a saving rate of 3.0 percent, this 50 percent sharing rule would allow the individual to keep 100 
Table 1

\section{Effects of Saving Rates and Guarantee Levels on Call Option Strike Prices}

\begin{tabular}{|c|c|c|}
\hline Saving Rate & Guarantee Level & Call Option Strike Price \\
\hline as percent of & as percent of & as percent of \\
\hline Covered Earnings & Benchmark Benefit & Benchmark Benefit \\
\hline 2.0 & 90 & 115 \\
\hline 2.5 & 90 & 150 \\
\hline 3.0 & 90 & 195 \\
\hline 2.0 & 95 & 103 \\
\hline 2.5 & 95 & 130 \\
\hline 3.0 & 95 & 166 \\
\hline 2.0 & 100 & $* *$ \\
\hline 2.5 & 100 & 116 \\
\hline 3.0 & 100 & 145 \\
\hline 2.0 & 105 & $* *$ \\
\hline 2.5 & 105 & 106 \\
\hline 3.0 & 105 & 130 \\
\hline
\end{tabular}

** These guarantee levels cannot be supported with the specified saving rate. 
percent of the annuity up to 119 percent of the benchmark and then 50 percent of the excess above that level with no limit.

These calculations have all assumed a real risk free interest rate of 4.0 percent, reduced by 40 basis points for administrative costs. A lower rate of return increases the cost of the put option and requires a lower cap for the equal-valued call option. With a saving rate of 2.5 per cent and guarantee level of 100 percent of the benchmark benefit, the cap declines from 116 per cent of the benchmark with a four percent real rate of return to 106 percent with a 3.75 percent real rate of return and to 98 percent with a 3.5 percent real rate of return. With a saving rate of 2.0 percent and a real return of 3.5 percent, the collar is just sufficient to provide the guarantee at a level of about 92 percent of the benchmark benefit.

\section{Concluding Comments}

This paper shows how market-based "accumulated pension collars" can be used to reduce the risk of investment-based Social Security reforms. These pension collars finance a put option guarantee at a chosen level of retirement income by selling a call option that limits or reduces higher levels of retirement annuities.

We have shown how to calculate some of the ways that an individual can guarantee that the combination of the traditional Social Security benefits and the Personal Retirement Account annuities will be at least equal to the benefits projected in the current Social Security law. Such a guarantee can be achieved with a saving rate as low as 2.16 percent of earnings. Higher saving rates or lower guarantee levels would permit individuals to have the possibility of receiving substantially higher levels of annuity payout.

The current analysis raises several issues for future research. We have, for example, assumed that all future annual earnings during the individual's working life are known at age 21 and therefore that the future PRA contributions are also known. How might the option design be modified to reflect the uncertainty of future earnings and how would that uncertainty affect the option pricing? This is complicated by the extent to which an individual can control those earnings by his or her personal decisions.

A related issue is raised by the assumption in our analysis that individuals commit to a particular guarantee level at the start of their working life and choose at that time the investment mix (e.g., the 60:40 stock bond portfolio) for life. In reality, some individuals will want to 
change both of these over time, perhaps in response to the cumulative performance of their investments. Options have a value along the time path even before retirement begins that would allow such changes to be made. Individuals might also select a collar based on some standard market portfolio while actually investing their funds in varying ways. ${ }^{19}$ An explicit analysis of this issue would be desirable.

The Social Security rules promise a benefit that maintains its real value (as measured by the Consumer Price Index) after the individual retires. The put and call options that we have priced are based on those real benefit levels. Although the existing Treasury inflation-indexed bonds provide a natural way of hedging such risk, they have a relatively low rate of return. An interesting question is what role such securities might play in an optimal hedging strategy, perhaps with a yield enhanced by the use of credit derivatives that raise the expected return by reducing the credit quality below that of the government bonds.

There are of course administrative issues and fiduciary questions about what kinds of firms might be allowed to sell pension collars, what their reserves would have to be, etc. Such issues are dealt with today for annuity and insurance products by a variety of government regulatory agencies.

The large scale use of pension collars might change the market price of risk, i.e., the prices of securities and the real interest rate. Although it would be interesting to explore general equilibrium models to see what light they can shed on possible changes in the price of risk as the demand for such pension collars grows, it is worth keeping in mind that the market in derivatives has grown explosively over the past decade and could be expected to do so in the future if a new demand for such products develops. ${ }^{20}$

Finally, the analysis should be extended to allow for bequests when individuals die before reaching retirement age and for the possibility of bequests even for those who die after the

${ }^{19}$ The payoffs of the put and call would then reflect the hypothetical portfolio corresponding to the standard market portfolio with the individual taking the risks associated with the differences between that standard portfolio and the particular portfolio that he has chosen.

${ }^{20}$ The volume of outstanding over-the-counter derivatives rose from less than $\$ 5$ trillion at the end of 1990 to nearly $\$ 60$ trillion at the end of 1999 . 
annuity has begun. Although we have examined those possibilities in an earlier paper, that analysis did not include the use of options. When options are included, there are questions about how the call option payoffs might be designed when individuals die before retirement and what kinds of guarantees, if any, might be sought for the size of bequest when individuals die before retirement (Feldstein and Ranguelova, 1999).

One of the advantages of a market-based system for dealing with risk is that it would allow individuals to select combinations that reflect their preferences. This individual discretion might be combined with a government requirement that any eligible PRA plan provide a guarantee of at least (say) 90 percent of the benchmark benefit but, subject to that requirement, individuals could be free to select whatever strategy of puts and calls they like. There is clearly great scope for the imaginative design of alternative ways of protecting retirement incomes.

Cambridge, MA

October 2000 


\section{$\underline{\text { References }}$}

Black, Fisher and Myron Scholes, 1973, "The Pricing of Options and Corporate Liabilities," Journal of Political Economy, 81, 637-654.

Bodie, Zvi, 1999, "Financial Engineering and Social Security Reform," forthcoming in Campbell and Feldstein (eds.), Risk Aspects of Investment Based Social Security Reform, University of Chicago Press, Chicago, IL.

Brown, Jeffrey, 1999, "Differential Mortality and the Value of Individual Account Retirement Annuities," forthcoming in Martin Feldstein and Jeffrey Liebman (eds.), The Distributional Effects of Investment Based Social Security System, University of Chicago Press, Chicago, IL.

Campbell, John Y,. Andrew W. Lo, and A. Craig MacKinley, 1997, The Econometrics of Financial Markets, Princeton University Press, Princeton, NJ.

Cox, John C. and Stephen A. Ross, 1976, "The Valuation of Options for Alternative Stochastic Processes," Journal of Financial Economics, 3 (January -March): 145-166.

Feldstein, Martin and Andrew Samwick, 1997, “The Economics of Prefunding Social Security and Medicare Benefits, NBER Macroeconomics Annual, The MIT Press, Cambridge, MA, 115-147.

Feldstein, Martin and Andrew Samwick, 1998a, "The Transition Path in Privatizing Social Security", Privatizing Social Security, Martin Feldstein (ed.) University of Chicago Press, Chicago, IL.

Feldstein, Martin and Andrew Samwick, 1998b, "Potential Effects of Two Percent Personal Retirement Accounts," Tax Notes, Vol. 79, No. 5, 615-620. An updated version is 
available with the title "Maintaining Social Security Benefits and Tax Rates through Personal Retirement Accounts: An Update Based on the 1998 Social Security Trustees Report,” NBER Working Paper No. 6540.

Feldstein Martin and Andrew Samwick, 2000, “Allocating Payroll Tax Revenue to Personal Retirement Accounts," Tax Notes, Vol. 87, No. 12, 1645-1652. NBER Working Paper No. 7767, July 1999.

Feldstein Martin and Elena Ranguelova, 1998, “Individual Risk and Intergenerational Risk Sharing in an Investment-Based Social Security System,” NBER Working Paper No. 6839, revised May 1999.

Feldstein Martin and Elena Ranguelova, 1999, "The Economics of Bequests in Pension and Social Security," forthcoming in Martin Feldstein and Jeffrey Liebman (eds.), The Distributional Effects of Investment Based Social Security System,University of Chicago Press, Chicago, IL. NBER Working Paper No. 7065.

Feldstein Martin, Elena Ranguelova and Andrew Samwick, 1999, "The Transition to InvestmentBased Social Security when Portfolio Returns and Capital Profitability are Uncertain,” NBER Working Paper No. 7016, forthcoming in Campbell and Feldstein (eds.), Risk Aspects of Investment Based Social Security Reform, University of Chicago Press, Chicago, IL.

Ingersoll, Jonathan E. Jr., 1987, Theory of Financial Decision Making, Rowman \& Littlefield Publishers, Inc., Savage MD.

McHale, John, 1999, “The Risk of Social Security Benefit Rule Changes: Some International Evidence," forthcoming in Campbell and Feldstein (eds.), Risk Aspects of Investment Based Social Security Reform, University of Chicago Press, Chicago, IL. 
Merton. Robert C., 1990, Continuous Time Finance, Blackwell Publishers Inc., Cambridge, MA.

Smetters, Kent, 1999a, "The Effect of Pay-When-Needed Benefit Guarantees on the Impact of Social Security Privatization", forthcoming in Campbell and Feldstein (eds.), Risk Aspects of Investment Based Social Security Reform, University of Chicago Press, Chicago, IL.

Smetters, Kent, 1999b, “The Equivalence Between State Contingent Tax Policy and Options and Forwards: An Application to Investigate the Social Security Trust Fund in Equities," mimeo. 
Figure 1

Retirement income at age 67 as multiple of benchmark benefit (saving 2.5\%)

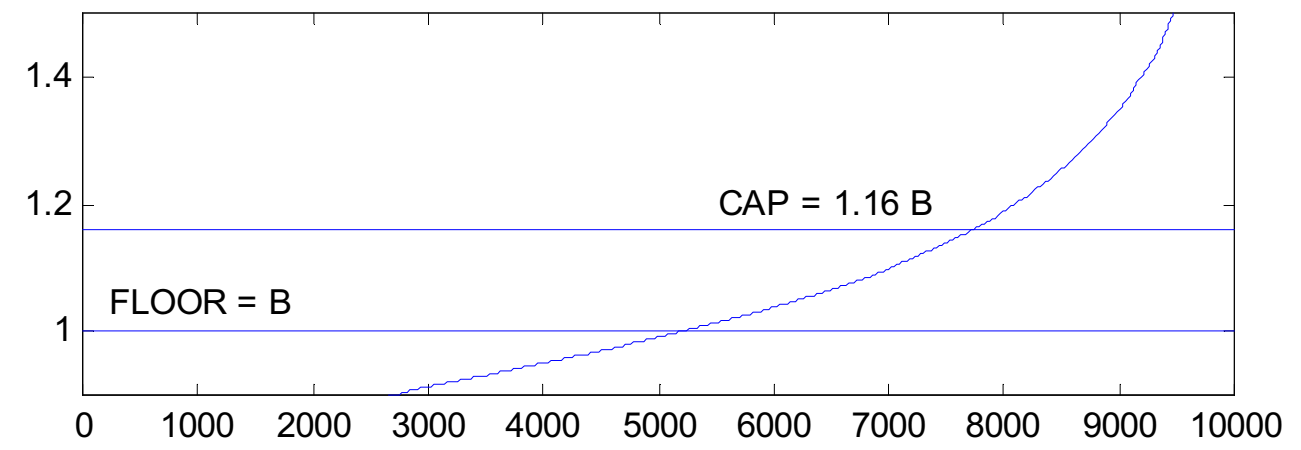

Retirement income with collar at age 67 as multiple of benchmark benefit (saving $2.5 \%$ )

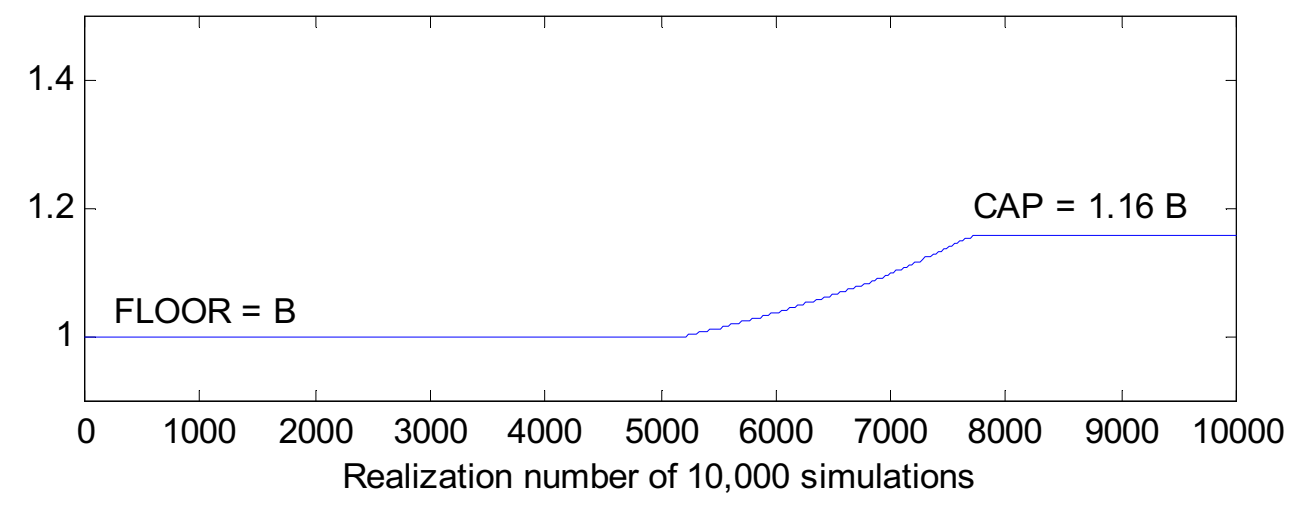

